\title{
El Villaurrutia de Reflejos
}

El camino poético que en el año 1938 llevará a Xavier Villaurrutia al momento de plenitud, con la aparición en Buenos Aires de la primera edición de su magnífica Nostalgía de la muerte, ya se hace claramente visible doce años antes con la publicación en México de Reflejos, ${ }^{1}$ primera colección reunida por el joven poeta. Desde la perspectiva de Nostalgia, obra que le confiere al autor su grandeza (grandeza hasta hory poco reconocida) no sólo entre los así llamados "Contemporáneos" de México, sino también en el amplio panorama del verso hispanoamericano actual, Reflejos adquiere importancia como precursor, como primer paso hacia una completa realización artística. Tanto la distancia, que a estas alturas nos proporcionan los años, como nuestro conocimiento de Nostalgia (en especial, de los noctumos) nos permiten releer con ojos nuevos la obra inicial. La relectura sería un acto anticipatorio, pero a la vez - $\mathrm{y}$ en esto también cabe insistir- un reencuentro con Reflejos como representante de un momento único, irrepetible, de una evolución creadora.

Al terminar el periodo que corresponde a sus primeras incursiones juveniles por el mundo de la poesía (composiciones apatecidas entre 1919 y 1923 en revistas y denominadas póstumamente como "Primeros poemas"), ${ }^{2}$ Villaurrutia comienza a lograr una cierta unidad de tema, estilo e imágenes la cual ha de dar a Reflejos su fisonomía característica. Ramón López Velarde, cuya influencia no faltaba en los versos del poeta adolescente, deja sentir su presencia aquí con mucha mayor fuerza. Alí Chumacero cita ejemplos de "la huella velardeana"

1 Los textos completos de Reflejos y de Nostalgia de la muerte aparecen en la edición definitva de las Obras de Villaurrutia, ed. Miguel Capistrán, Alí Chumacero y Luis, Mario Schneider, 2a. ed. aumentada, México, 1966, en las pp. 26-43 y 4.4-73 respectivamente. La primera edición de Reflejos (México, 1926), reunió todas las composiciones incluidas en la colección póstuma a excepción de "Poesía", que apareció por primera vez en Ulises, núm. 4, octubre, 1927. De acuerdo con los editores de las Obras, incluyo también este poema al referime al Villaurrutia de Reflejos, principalmente por razones de proximidad temporal.

2 Pp. 3-25 de las Obras. 
en ambos grupos de poemas, ${ }^{3}$ la cual se manifiesta, entre otras cosas, como una creciente discriminación en la selección de imágenes; pues cuando Villaurrutia inicia la composición de los poemas que habrían de aparecer en Reflejos, su mundo poético ya va reduciéndose a las escenas provincianas tan propias del autor de La sangre devola y Zozobra. Tomás Segovia lamenta "ese provincialismo voluntario - y un poco falsoadoptado por amor a López Velarde", que él atribuye a los poemas más antiguos, y nota el contraste con la nueva delicadeza de tono en Reflejos. ${ }^{4}$ Esto no implica, sin embargo, que se disminuya la atracción que la vida provinciana ejerce sobre el poeta como fuente de imágenes. En efecto, Reflejos abunda en visiones de rusticidad exterior e interior: paisajes con arroyos y árboles en "Aire", la tranquilidad de la naturaleza doméstica en "Jardín", la pequeña comunidad en "Pueblo" y utensilios caseros en "Interior".

Lo que presenciamos aquí es un proceso de reducción que se completará más tarde con la economía de imágenes que caracterizará a Nostalgia de la muerte. En este momento el poeta se decide por una realidad concreta, de fronteras fácilmente identificables: el mundo de las sensaciones visuales, auditivas y táctiles más reconocibles para quien reside en el campo. Entre las imágenes contenidas en este mundo hallamos prácticamente todas las que formarán la base de la obra principal de Villaurrutia - aunque aquí todavía aparecen a menudo sin llegar a desarrollarse por completo, sin asumir las funciones que después las caracterizarán. Por ejemplo, el agua, origén de las importantes imágenes marinas de Nostalgia, comienza a adquirir un lugar significativo propio en Reflejos. Quizás sea su función más obvia el prestar posibilidades imaginativas a paisajes y eventos que tienen lugar en un ambiente rural. Así en el poema que da nombre a la colección, Villaurrutia recrea una escena de amor en la cual el rostro de su dama se refleja en el agua de un manantial, a la cual es también comparado. En el segundo poema de esta colección titulado "Noche" ("Cielo increíble. ..") el "agua incansable" de un arroyo sirve para personificar el paisaje nocturno, dando a los caminos rurales el aspecto de "arroyos que se han dormido". "Arroyo" regresa a la visión de agua en movimiento y crea una rápida serie de impresiones visuales, gustativas y táctiles:

¡Qué du!ce el agua

disolviendo sales!

3 Prólogo a Villaurrutia, Obras, pp, xvi-xviii.

4. "El mundo de Xavier Villaurrutia", Revisha de la Universidad de México, VIII, 10, junio 1964, p. 2. 


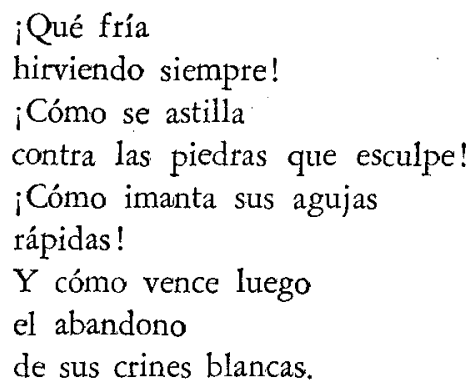

El uso del agua para comunicar a la naturaleza una nueva y animada frescura continúa en "Azoteas", donde el cielo es el mar y las nubes en movimiento se describen como "largos talones / de olas maltratadas".

A1 mismo tiempo, no podemos dejar de notar aquí, en Reflejos, cómo se dirige el poeta, ya en esta etapa temprana, rumbo a Nostalgia y a una superior maestría en el uso de esta imagen. En la obra posterior el agua aparecerá bajo la forma de un océano en cuyas profundidades el cuerpo humano se hunde lentamente mientras llega la noche. También esta identificación de la noche con el mar hará posible que la conciencia se encuentre a sí misma "dentro del agua que no moja" ("Nocturno en que nada se oye") - cubierta por un fluido que sobrepasa en mucho al agua y que se presta a la expresión de la experiencia interior mejor que a la descripción de la realidad externa. Muestras de este nuevo tratamiento a imágenes anteriormente empleadas aparecen a veces en Reflejos:

Nos moja, al correr, un agua

oscura y tibia. Nos moja

un agua sin agua.

("Viaje")

La primera de las dos poesías intituladas "Noche" ("Qué tic-tac en tu pecho...!") presenta la fatiga de los amantes como un reposo y un sufrimiento en los que ambos caen "como en un pozo / sin fin de luz de aurora...". En "Poesía" se habla de

las palabras

que salen del silencio

$\mathrm{y}$ del tanque de sueño en que me ahogo,

y en el poema "Reflejos" el agua del manantial, la cual representa la cara de una mujer, al final revela su nueva dimensión hundiendo tepen- 
tinamente el reflejo de ella en las inaccesibles profundidades. "Incolor" expresa la decepción de que el agua tan sólo pueda reflejar los brillantes colores del paisaje y no se muestre como el líquido incoloro que podría simbolizar la vida interna del poeta. Es así como éste busca en vano

$$
\begin{aligned}
& \text { un paisaje, un paisaje } \\
& \text { en que el agua, } \\
& \text { no copiando ningún color, } \\
& \text { sea del color de mi alma. }
\end{aligned}
$$

La búsqueda continúa en la corta composición "Agua", donde la sed del poeta es tal que el agua que lo satisfaga ha de tener una mayor realidad, que abarque el sueño y el despertar con todo lo que sugieren como metáforas de experiencia personal.

La noche y los suenos ilustran otra manera en que Villaurrutia prefigura en Reflejos el mundo de Nastalgia. Mientras, como el título sugiere, el poeta en su primera colección hace lo concreto visible valiéndose de los rayos del sol para darle color y multiplicarlo, también añade momentos de oscuridad después de la puesta del sol, cuando las luces se han extinguido $\mathrm{y}$ son precisamente estos momentos los que llegarán a predominar en la obra posterior, convirtiendo así el ambiente soleado de estas primeras composiciones en el oscuro de los nocturnos. Tal transformación se anticipa en los dos poemas del título "Noche", en "Pueblo", "Amplificaciones", "Cinematógrafo", el tercero de la serie "Lugares" ("Yo te dejaba ir, los ojos") y en las ocho poesías de la "Suite del insomnio". También aparece aquí el fenómeno nocturno del sueño, tan importante en Nostalgia de la muerte. Pero, a diferencia de la obra posterior del poeta, en que la misteriosa oscuridad de la noche se mantiene dentro del marco del sueño que ocurre en ella ("todo lo que la noche / dibuja...." equivaldrá a "todo lo que el sueño / hace palpable...." en el primero de los 1tocturnos), el sueño que proporciona el tema y da nombre a una composición de Reflejos no revela muestras de la realidad nocturna que lo engendra. En cambio, el poema "Sueño" conduce al poeta fuera del ámbito de la noche, hacia el sencillo y radiante mundo de sol y colores:

En el sueño reíamos

al sol naranja, agrio

en los ojos, húmedo

en las sienes. 
Rodaba el sueño

y nosotros rodábamos

en el verde increíble

del prado.

A pesar de todo, ya esta colección nos da, aunque momentáneamente, una idea del papel que desempeñará el sueño en la poesía posterior de Villaurrutia, pues en ésta la imaginación y la expresión formarán con el sueño una telación que nace con la imagen del "tanque de sueño", ya notada en "Poesía", y que incluirá la íntima participación de lo onírico en los procesos perceptor y creador.

Además de estas imágenes fundamentales a Nostalgia (especialmente a los noctumos) - el mar, la noche y el sueño-, aparecen en Reflejos otras que tendrán un papel importante en la obra posterior del poeta. La frecuente aparición de espejos y la insistencia en la oculta presencia del corazón son dos ejemplos cuya importancia requiere que se los trate posteriormente aquí. Por el momento nos convendría señalar varias imágenes desarrolladas con menos esmeto en la primera colección del poeta, pero que se continúan en la siguiente. Una de éstas es la calle. En los nocturnos la palabra "calle" formarái parte de una realidad poética que expresa la soledad del hombre y su consiguiente temor: "entre las sombras de una calle desierta, / en el muro, lívido espejo de soledad" ("Nocturno miedo"). Ya habíamos visto en Reflejos la transformación de la calle de un marco pintoresco a un medio de expresar el temor y la duda. Cuando la poesía lo abandona, el poeta se siente repentinamente vulnerable en su universo hostil, "como un hambre desnudo / en medio de una calle de miradas" ("Poesía"). En "Pueblo" el agua del río y el firmamento son "vías", pero también "vidas paralelas" que finalmente se encuentran, sin embartgo, en la lejana ciudad donde se han refugiado los antiguos habitantes de un pueblo desierto. Las "calles" presentadas en el poema del mismo nombre resultan ser el marco de una temible reunión con las realidades exteriores, las cuales son verdaderamente proyecciones del yo - reflejos, ecos y la sombra del cuerpo-, y como un rechazamiento progresivo a todo lo que es percibido por los sentidos, "hasta quedarme solo, / solo, sin soledad".

Otra imagen importante por el precedente que establece es la de la casa, específicamente las habitaciones, puertas y ventanas. Nuestro conocimiento de la Nostalgia nos llamará la atención en Reflejos sobre la conexión entre el ojo humano, que al cerrarse produce una ceguera, y la apertura de una casa: "cuando los ojos cierran sus ventanas" ("Nocturnos 
eterno"). El lector de Reflejos siente que Villaurrutia está consciente de las posibilidades poéticas ofrecidas por esta serie de imágenes. Las. ventanas no sólo aparecen como un atributo de las casas, sino que, por: una transparencia común, se identifican con el aire y el agua ("Cézanne"). Desde el interior de una casa la ventana "rebana un trozo de jardín" ("Jardín"). En "Mudanza" el poeta visualiza la casa como si fuera echada por la ventana que forma parte de ella. Y los tranvías se convierten en

\author{
Casas que corren locas \\ de incendio, huyendo \\ de sí mismas. \\ ("Tranvías")
}

El único poema de este grupo que anticipa el uso posterior de las imágenes de la casa es "Amplificaciones", donde la soledad del pocta se extiende físicamente
como las caras de ayer asomadas para adentro
en el marco de sus ventanas,

efectuando no sólo la identificación de los ojos con las ventanas, sino tam_ bién la evocación de un mundio concreto exterior que dirige al lector a una experiencia interior.

Si Villaurrutia todavía no ha descubierto totalmente la relación metafỏrica entre la casa y el ojo, muestra en el poema "Aire" que ya ha comprendido las posibilidades poéticas de lo que pronto será una de sus imágenes auditivas predilectas. En los nocturnois — de forma más dramática en el "Nocturno en que nada se oye" - la concha espiral será asociada con el oído, su forma sugiriendo la de la oreja. Se verá entonces cómo la representación de la percepción auditiva lleva al poeta a una destrucción tal del lenguaje, que las palabras se convierten en una serie confusa de sonidos que imposibilitan cualquier revelación de significados. Algo de esto aparece ya en Reflejor, donde el aire "juega a los sonidos" y "llena con ecos de plata de agua / el caracol de los oídos" ("Aire"), prefigurando así la marea oceánica que en los noctumos inundará el oído.

"Aire" nos lleva a la serie final de imágenes significativas en Reflejos y Nostalgia. El aire y ciertos componentes semivisibles de la atmósfera — polvo, ceniza y humo- que serán especialmente importantes en la 
fase posterior de Nostalgia, se introducen aquí. En el poema al cual nos acabamos de referir, al aire se le asigna una función que será en lo sucesivo realizada por los órganos humanos de la percepción: rechazar la realidad exterior tal como es representada convencionalmente, pintarla como inestable y por consiguiente no ya definible como realidad. De esta actitud frente a la realidad, que aparece aquí como característica de $R e$ flejos, se hablará detenidamente más adelante en este estudio. Por el momento baste decir que en "Aire" este último "juega" con el morimiento y la inmovilidad, con la distancia y el color, con los scnidos y con las memorias. El papel que desempeñará el aire en Nostalgia se anuncia más claramente mediante su función en "Interior" y "Domingo", donde su naturaleza etérea se transforma en una solidez que volverá a afirmarse con la imagen del "aire duro y frío" ("Nocturno en que habla la muerte") de la abra posterior. "En "Interior" el aire experimenta un proceso de endurecimiento (compárese el tercer verso con el "aire de vidrio" del "Nocturno en que nada se oye"):

El aire que vuelve de un viaje,

lleno de dorado calor, se hiela en un marco para ser espejo

y cuadro de comedor;

y en "Domingo" el poeta llega a ver "el aire incoloro / y poroso" que lo rodea en el campo. El aire lleno de humo y cenizas que simbolizará al silencio de la -muerte en Nostalgia, aparece en el cielo de "Viaje" como la emisión de un tren y como "un aire / cenizo, lento" (el cielo invernal de "Muerte en el frio" será sólo "la ceniza / de algo que ardió hace muchos, muchos siglos", y el polvo, humo y ceniza de "Cuando la tarde..." serán "lentas como el trabajo de la muerte") que es "un aire sin aire". En "Azoteas" el horizonte proyecta "un humo delgado", en tanto que en la primera "Noche" el presentimiento de la muerte se asocia a "este polvo blanco".

Las imágenes que nos han ocupado hasta ahora no son necesariamente las más importantes para Reflejos mismo, pero son significativas porque volverấn a hacer acto de presencia, aunque a menudo en papeles diferentes, en Nostalgia de la muerte. Aunque el poeta ya comienza a usar algunas para manifestar esa experiencia personal de desasosiego interior que adquirirá tanta importancia en la obra posterior, más llama la atención en Reflejos su tendencia a tratar las imágenes en general como un punto de partida, de ver en la presencia de lo concreto un preludio a 
desarrollos temáticos que pronto lo opacarán. La descripción nos lleva a la meditación o quizás a una intuición repentina. Si bien las preocupaciones y las actitudes que emergen, con frecuencia presentan en forma germinal las que se encontrarán luego en Nostalgia, el hecho de nacer de un mundo concreto ya establecido implica un contraste entre Reflejos y Noskalgia, pues en ésta el mundo exterior y la experiencia interna producirán conjuntamente una totalidad sin diferenciar (con las posibles excepciones de algunas composiciones del grupo de las "Nostalgias", especialmente "Nostalgia de la nieve" y "Cementerio en la nieve").

Observando a Villaurrutia trazar los caminos que habrían de llevarlo al promontorio temático de su época madura, notamos la intención de usar marcos provincianos para algo más que fines remanente descriptivas. La sensación de la soledad, por ejemplo, brota de un encuentro anterior con los objetos y fenómenos de inmediaciones físicas particulares. En el poema "Soledad" Ia conciencia de un aislamiento angustioso resulta de la contemplación del retrato de una mujer. Frank Dauster observa cómo "crece la melancolía mientras se aguza dentro del poeta su sentimiento de soledad que lo sigue desde los ojos del retrato...." $\mathrm{El}$ proceso por el cual esto ocurre comienza con la observación de "la mujer de ese cuadro". La meditación sobre esta presencia concreta da lugar al reconocimiento de la existencia de la soledad —una condición peculiar visible en el retrato y que se identifica con lo que el poeta ha llevado siempre dentro de sí. El "sentimiento de soledad" que Dauster ve cristalizando a medida que el poema avanza, es, al menos en este sentido, el resultado del contacto visual con un objeto localizado fuera del yo, en un marco doméstico convencional. De manera similar, la acción de la aguja en el disco de "Fonógrafos" y el escasamente alumbrado "cuarto del pueblo, / fantástico y desnudo" de "Amplificaciones", son puntos de partida establecidos, sin los cuales el drama de soledad del poeta no podría representarse. En cuanto el escenario está listo, los elementos del yo interior del poeta pueden salir a relucir, aun a costa de transformar èl mundo exterior que los ha evocado. Así la soledad convierte al fonógrafo en una bestia que nos roe, y su aguja en un cuchillo que atraviesa el corazón ("Fonógrafos"); y en "Amplificaciones" presta su ominosa presencia a sombras que caen a través de una pared y a insectos que rodedn la llama de una vela.

El problema de la percepción, preocupación especialmente importante en los mocturnos, se plantea y se resuelve aquí de la misma manera que la

5 Ensayas sobre poesía mexicana: Asedio a los "Contemporáneos" (México, 1963), pp. 17-18. 
soledad. Algunos poemas ofrecen indicaciones de lo que después se convertirá en una profunda desconfianza en el valor de los sentidos como medio de confirmar la existencia de un mundo real y de descubrir sus leyes. En el retrato de la mujer el poeta cree ver su propia condición reflejada simpatéticamente. En el último verso, empero, el poeta sugiere, a modo de reflexión posterior, que lo que él cree haber percibido en el otro quizás sea su propia soledad actuando sobre la facultad visual y permitiendo tan sólo la ilusión de la vista externa:

$$
\begin{aligned}
& \text { Y cuando lloro - algunas veces lloro- } \\
& \text { también sus ojos se humedecen, } \\
& \text { o será que los miro con los míos. }
\end{aligned}
$$

("Soledad")

El aire es también ocasión para la duda sobre la posibilidad de que los sentidos en general pudieran llegar a una percepción real, pues no sólo antepone confusas "vidrietas entre los ojos y el paisaje", sino que convierte el oido en mera resonancia de ecos en el aparato auditivo y se vale de tretas con la percepción temporal que es la memoria ("Aire"). El interés de Villaurrutia en el proceso de la percepción, al igual que en sus objetos, comienza a manifestarse en poemas como el primer "Lugares" ("Vámonos inmóviles de viaje...."), donde una excursión port el campo lo lleva al contraste entre "la tarde de siempre / con otra mirada" y "la mirada de siempre / con otra tarde", dirigiendo la atención del aparato sensorial hacia afuera $y$, simultáneamente, hacia el interior.

Del universo de Reflejos brota también el estado emocional de una expectativa acompañada de intensa lucidez - la condición mental en la que el poeta confrontará su situación en los nocturnos. La primera "Noche" es un momento de insomnio que anticipa la solitaria vigilia del poeta en "Nocturno amor"; sumido en oscuridad pero atento al menor ruido, expresa su actitud con la orden "aguardemos". La segunda "Noche" tiene "una luz tan morada, / tan salpicada de oro", que su claridad sugiere la tarde y anticipa la "luz nocturna" que mantendrá al hombre despierto y tenso en "Nocturno miedo". En "Amplificaciones" la oscura habitación de un pequeño pueblo halla al poeta "sobrecogido", sensible a movimientos y sonidos semipercibidos que resultan en un misterioso "presagio". La más obvia evidencia de la creciente fascinación de Villaurrutia con la vigilia nocturna y la lucidez, se encuentra, empero, en la "Suite del insominio", la cual encabeza los siete cortos poemas que aparecen al final de Reflejos. Aquí la atmósfera provinciana es transformada 
por el insomnio del poeta en una rápida serie de impresiones sensoriales, en su mayoría auditivas, que se imponen a la conciencia alerta pero no son asimiladas por el entendimiento. Como en los poemas anteriores, la noche simplemente "juega con los sonidos" ("Ecos") y no recompensa al vigilante poeta con el reconocimiento o la comprensión de una realidad coherente.

En un grado mucho mayor que en Nostalgia Villaurrutia suplementa en Reflejos sus esfuerzos para penetrar la realidad concreta inanimada concerniéndose directamente con otros seres humanos. Mientras en Nostalgia usará la presencia de la mujer para dramatizar y confirmar el abismo que lo separa de los demás (en el "Nocturno amor", por ejemplo, el poeta amante se verá junto a un "cuerpo más muerto que muerto"), vemos aquí al menos la creencia inicial en la posibilidad y valor de dirigir su expresión y acción personales al exterior hacia individuos favorablemente dispuestos. El frecuente uso de la segunda persona y de la primera persona del plural indica la conciencia de una experiencia personal compartida en vez de puramente individual. "Eres la compañía con quien hablo", le dice a la poesía personificada ("Poesía"). "En el poema "Reflejos" recuerda un momento que forma parte de su pasado al igual que del pasado de otro. En "Sueño" describe la realización de intimidad con el tú usando las formas verbales plurales "rodábamos" y "reíamos". La primera "Noche" trata el tema de la unión física en el amor erótico. Tanto "Soledad" como el primer poema intitulado "Cuadro" ("Fuera del tiempo, sentada....") sugieren la posibilidad de comunicación entre el poeta y las mujeres cuyos retratos parecen revelar vidas interiores semejantes a la suya. Rn éstas y en otras ocasiones no podemos evitar reconocer la idea implícita de una comunidad de experiencia que lo impulsa a buscar y cultivar encuentros fuera del yo.

Aunque Reflejos no niega a los encuentros personales desde el principio la posibilidad de conducir a un satisfactorio intercambio de experiencias, anticipa la atmósfera de futilidad evidente, por ejemplo, an "Nocturno amor", prestándole un aire de inestabilidad o de irrealidad al momento inicial de contacto, de modo que una comunicación auténtica nunca ocurre. Doña Poesía de repente comienza un diálogo con su anfitrión, pero de manera igualmente repentina desaparece al "menor tuido", dejándolo solo y vulnerable ("Poesía"). La mujer del poema "Reflejos" no es más que un recuerdo, y aun en la memoria existe tan sólo durante el instante en que el agua del manantial es suficientemente mansa para reflejar sus facciones. La visión del gozo libre de cuidados del amante 
está circunscrita por la insubstancialidad del sueño en que tiene lugar, y el poeta se pregunta si lo que él ha soñado será realizadio jamás:

$$
\begin{gathered}
\text { ¿Nos juntará la vida } \\
\text { como el sueño? } \\
\text { ("Sueño") }
\end{gathered}
$$

Cuando los ojos de la mujer en el cuadro de "Soledad" "me quisieran decir que no estoy solo", indican que el poeta está unido a esta reprer sentación bidimansional de una cara humana sólo por el hecho de que él, como el sujeto, experimenta una soledad infranqueable. $\mathrm{Y}$ en el primer "Cuadro" la mujer del retrato atrae la atención del poeta por la ambigüedad y misterio de su actitud más bien que por nada que ella revele sobre sí. La primera "Noche" es probablemente la composición más cercana en espíritu a los poemas de amor que aparecerán al principio de Nostalgia, pues es el único momento en Reflejos en que el amor erótico aparece unido al importantísimo tema de la muerte. El abrazo de los amantes no representa una unión de lo más íntimo de sus seres, sino que, como en el posterior "Nocturno de la alcoba", sólo los une irrevocablemente al principio de destrucción total, "provocando el segundo de muerte", cuando terminará incluso la posibilidad de la comunicación.

Es esta sensación de la fugacidad del mundo exterior (incluso las personas) la que, quizás más que ningún oțo factor, separa a Reflejos de su sucesor y lo coloca en una trayectoria poética cuyo apogeo será alcanzado por este último. Por una parte nos damos cuenta de que, a pesar de dar estos poemas muestras de escepticismo sobre el valor existencial último de personas y cosas presentes en apariencia, no se entregan a la duda absoluta de la realidad personal y exterior de la que partirá Nostalgia de la muerte, pues hemos visto que presuponen un mundo concreto reconocible y hasta refuerzan su autenticidad por medio de la descripción. Por otra parte, aunque una cierta esfera de existencia es aceptada como tal en Reflejos, el autor descubre que su forma se resiste a la identificación y definición real, ya que todo cuanto existe cambia continuamente en el tiempo. Las palabras con que Arturo Torres Rioseco trata de expresar el efecto total de estos pocmas on el lector - "un tenue perfume, un simulacro de sanrisa, un fragmento de emoción bajo una imagen que tiembla y se disuelve"-6 podrian ser utilizadas casi con igual exactitud para caracterizar los noctumos. Lo que verál el lector como el verdadero punto de diferencia es que aquí la fragilidad y la insubstancia-

\footnotetext{
- Ensayos sobre literatura latinoamericana (México, 1953), p. 205.
} 
lidad no expresan una negación absoluta (o ignorancia) de la existencia, sino el reconocimiento de que el hecho de existir inevitablemente acarrea la transformación en el tiempo de lo que existe.

El tratamiento de Villaurrutia al tiempo mismo demuestra esta distinción. La temporalidad es un factor tan real para el poeta, que se identifica con el pulso de la vida en el cuerpo humano:

\author{
mis sienes dan la hora \\ en no sé qué reloj \\ puntual y eterno. \\ ("Amplificaciones")
}

El corazón en particular crea un sentido del tiempo más vívido y nuevo: se convierte en un "corazón avaro" que registra "el metal / de los instantes" ("Reloj"). Este movimiento temporal percibido interiormente se apresura y retrasa según el ritmo del corazón:

¿Qué tic-tac en tu pecho

alarga la noche sin sueño!

(primera "Noche")

El corazón realiza su propósito sólo cuando regula el tiempo, acelerando o decelerando sus latidos ("Jardín" y "Viaje"). En Nostalgia también se distinguirá el "monumento tan lento" ("Nocturno en que nada se oye") del instante que contiene a la eternidad y también se notará cómo ambos nacen en la conciencia del poeta frente a una realidad que experimenta en su interior. Esta conciencia conducirá a una negación de la realidad, mientras que en estos poemas la relación del movimiento temporal con el ritmo interior de la vida implica una afirmación del tiempo como un principio fundamental de la realidad.

En lo referente a Nastalgia, se verá cómo la negación de la temporalidad, según la acepción común y corriente de la palabra, acarrea el correspondiente énfasis en la realidad puramente espacial, logrado por las manecillas del reloj (como en "Décima muerte", VI). El movimiento en el espacio reemplazará así la progresión de momentos en una dimensión temporal, y de esta manera permitirá que el poeta se vea simultáneamente inmovilizado por la falta de tiempo y viajando en el mundo de la distancia física. Lo que es particularmente interesante en Reflejos es que, aunque Villaurrutia todavía no ha llegado al punto de aceptar una visión del mundo que pudiera llevarlo a repudiar lo temporal, mues- 
tra sin embargo el deseo de alcanzar una nueva manera de concebir y representar poéticamente el tiempo y el espacio. La paradoja del viaje inmóvil aparece por primera vez aquí —antes que al poeta se le haya ocurrido convertirlo en la parte lógica de una visión total de la realidad. En el primer poema de la serie "Lugares" toma la forma de un viaje en el interior del yo: el primer verso, "Vámonos inmóviles de Viaje", es una orden de viajar interiormente hacia el centro de percepción, y no exteriormente hacia un destino geográfico. De esta manera Villaurrutia anticipa los hechos del "Nocturno en que nada se oye", donde el "interminable descenso" describirá un viaje que tiene lugar en el interior del órgano de percepción. En "Viaje" el poeta usa la experiencia de la excursión en tren para presentar el fenómeno de la falta de movimiento (en un coche) acompañado de movimiento a lo largo de carreteras que atraviesan el pensamiento al igual que la distancia física:

¡Ay! Y nos vamos pensando lejos, can el tren silbando, sin movernos ni cansarnos.

$¡$ ¡Ay! Y nos vamos pensando sin volver adonde estamos.

Así, robando la luz, seguimos sin llegar y $\sin$ partit.

La representación espacial del tiempo se anuncia en "Interior" cuando el poeta ve "los días de la semana" en una serie de cristales y en el "Domingo" que aparece "detrás del tren / persiguiéndome...." En "Fonógrafos" su melancolia llega a una negación abrupta y petulante del tiempo:

$$
\begin{aligned}
& \text { El presente y el futuro } \\
& \text { los inventaron } \\
& \text { para que no lloráramos.... }
\end{aligned}
$$

En todo caso la relación entre el tiempo y el espacio que caracteriza a Reflejos dándole su cualidad peculiar, lleva consigo la aceptación -incluso la dolorosa conciencia - de ambos conceptos en su significado normal. En estos poemas a Villaurrutia raramente le falta el sentido de movimiento dentro del cual los momentos se escapan irrecuperablemente, 
haciendo lugar a otros. Tampoco olvida el potencial de la realidad concreta para ese movimiento que ocurre dentro de un determinado marco temparal y que resulta en nuevas relaciones espaciales de los elementos entre sí -es decir, en un cambio. Frente a un mundo exterior que el tiempo y el espacio han sometido a una transformación continua, la misión del poeta se convierte en ver lo que pueda haber de permanente y sea por lo tanto definible como realidad. El carácter primariamente visual de esta indagación se sugiere con el título Reflej $x$, que en el contexto de estos poemas indica un esfuerzo por formular una visión ordenada de la vida para capturarla, estabilizándola al revelar de repente su imagen en una superficie de área limitada.

De manera diferente a lo que se observará en la obra posterior, los reflejos podrían interpretarse aquí como tentativas de poner el mundo en un foco definible. En Nostalgia, como también en Canto a la primavera, última colección del poeta, la imagen reflejada, esencialmente una duplicación, simbolizará el fracaso del yo al querer avanzar hacia una conciencia significativa del mundo; es allí que el espejo, frente al cual se ve el poeta al final de su búsqueda del saber, manifestará concretamente que la percepción y el deseo no pueden penetrar más allá del yo. Este uso de lo reflejado para simbolizar no al esfuerzo mismo, sino al resultado del esfuerzo (en el "Nocturno de la estuatua", para citar un ejemplo) no está ausente de Reflejos. La poesía es personificada con su "piel de espejo", lo cual permite al poeta verse sólo a sí mismo y a sus esfuerzos de percepción ("Poesía"). Los "espejos de silencio" son todo lo que el aire inos deja, de modo que, en vez de progresar hacia un nuevo conocimiento, podemos tan sólo regresar a "los años vividos" ("Aire"). De manera similar la noche nos provee no con genuinas intuiciones, sino con "espejos / de sonidos", o ecos de lejanos sonidos ("Eco"); y la luz matutina sirve sólo para llenar el espejo con

$$
\begin{aligned}
& \text { un rincón para copiar } \\
& \text { exacto, eterno. } \\
& \text { ("Espejo") }
\end{aligned}
$$

El poeta evita la vista de su propia imagen para no tener que enfrentarse con su incapacidad de percibir nada que no sea él mismo:

Caminar sin que los espejos

me pongan enfrente

¡tan parecido a mí!

$$
\text { ("Calles") }
$$


A pesar de estos anticipos de los poemas posteriores, la primera colección de Villaurrutia concibe la imagen reflejada principalmente como un posible medio de conferir permanencia a un mundo cuya fuerza motriz impone cambio constante; el hecho de que este medio no pueda lograr el fin deseado es la verdadera fuente de la desilusión peculiar a Reflejos. En el poema que da título a la obra, la tensión entre la representación "tan muda y tan quieta" de la vida y el dinamismo de la vida -un continuo proceso de convertirse en algo diferente a lo que existía anteriormente- encuentra su resolución dramática cuando "el metal de los reflejos" producido en la superficie del agua, de repente paraliza el "rostro movido" de la mujer, convirtiéndolo en diafanidad y quietud inesperadas:

$$
\begin{aligned}
& \text { cuando el agua } \\
& \text { como que ensamblaba } \\
& \text { sus planos azules, } \\
& \text { un instante inmóvil. }
\end{aligned}
$$

Es sustantivo "instante" y la ocurrencia de este hecho fortuito "sólo en un momento" indican que la acción del tiempo no permitirá que la realidad sea verdaderamente capturada y sujetada por el reflejo, y en efecto la superficie en la cual ocurren los reflejos se quebranta inmediatamente con la fragilidad del cristal y hace desaparecer a la imagen:

$$
\begin{aligned}
& \text { ¡Ay, como si alguien } \\
& \text { golpeara en el agua, } \\
& \text { tu rostro se hundía } \\
& \text { y quebraba! } \\
& \text { ¡Ay, como si alguien } \\
& \text { me hundiera el acero } \\
& \text { del agua! }
\end{aligned}
$$

Así el tema del amor fugaz recibe una nueva dimensión cuando el poeta lo presenta dentro del contexto de un mundo concreto, cuya autotransformación en el tiempo no puede ser detenida por ningún intento de capturar su imagen. Como para subrayar este hecho, la superficie reflejada se hace añicos. Esto pasa de nuevo en "Puzzle", donde los elementos mutables e inestables de la realidad se presentan bajo la forma de "el espejito roto entre la lama", y en "Arroyo", donde la luz del sol: 


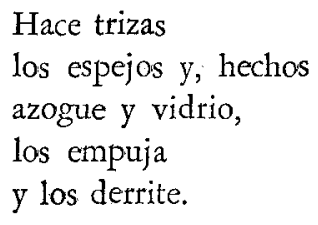

Los reflejos producidos por los espejos y superficies líquidas son sólo las indicaciones más concretas de lo que en términos generales es fundamentalmente una búsqueda de la forma; y en la resistencia implacable de la vida a que se le imponga forma, estriba la situación básica de estos poemas, pues el interés de Villaurrutia sobrepasa fenómenos naturales y artificiales específicos, llegando hasta la idea misma de forma, expresada visualmente en líneas y planos. Jorge Cuesta nota la gran deuda que Reflejos debe a la familiaridad de su autor con las artes plásticas, y observa cómo sus penetraciones en éstas prenden raíces discretamente en su atte poética:

Inconforme con el juego simple de las formas externas, no construye su poesía con materiales ruidosos - cláxons, radio, tumultoni es el parnasiano de los mármoles fríos or el poeta sensual de los colores. La plástica de su poesía se ajusta mejor al equilibrio de las formas, al dibujo de los objetos, a la calidad de la materia empleada, a la estética de las actitudes. Sus mujeres siempre vistas en retrato, sus paisajes un poco naturalezas muertas, explican el cambio de formas por posturas internas, finas como el temblor de una línea y que son sus emociones poéticas. ${ }^{7}$

Para Elías Nandino (quien, quizás injustamente, decide ignorar el posible valor temático de la forma) "todo el libro está hecho con una intención puramente plástica. Es como una serie de fieles instantáneos que reproducen la impresión visual que se las inspiró, sin más trascendencia que la justeza, color y dibujo, que un buen pintor usaría para reproducir en las telas sus 'naturalezas muertas' preferidas". 8

Como consecuencia de esta sensibilidad visual, la incapacidad del hombre de Reflejos de inmovilizar y estabilizar un mundo esencialmente dinámico, se expresa, en primer lugar, como el fracaso de las construcciones geométricos al intentar prevalecer sobre la ausencia de forma. En el poema "Reflejos" notamos que Villaurrutia tiende a reducir la natu-

7 Antología die la poesía mexicana moderna, México, 1928, p. 201.

8 "La poesía de Xavier Villaurrutia", Estaciones, I, 1956, p. 461. 
raleza a líneas rectas y superficies planas: el agua está hecha de "planos azules" y la luz del sol aparece como "rayas blancas". La impotencia en que está la superficie reflectora de mantener su imagen se manifiesta al romperse repentinamente de manera caótica y desaparecer de la vista. En "Jardin" sentimos claramente la tensión entre el esfuerzo por alcanzar la forma, representado por "la moldura de la ventana" y el plan geométrico del jardín, y el "laberinto" real, aunque no intencional, constituido por sus senderos. Esta situación lleva al poeta a preguntarse por qué la realidad rehusa someterse a la forma, y sus palabras finales sugieren que la realidad misma es fundamentalmente paradójica y sujeta a leyes que él sólo puede comenzar a entender:
¿Por qué la vida se complica
como el vuelo de esa golondrina
que burla toda la geometría?
Pero también la golondrina
atraviesa lanzando un grito
- se alcanzó rápida y derecha-,
herida, ella misma es la víctima
y la flecha.

No sólo los elementos formales de las artes visuales, sino el arte mismo pasa a formar parte de la poesía de Reflejos al emplear Villaurutia el cuadro para expresar su anhelo de forma. El aire que se hiela en un marco se convierte en un espejo y un "cuadro de comedor" ("Interior"). La tercera composición de la serie "Lugares" trae a la mente la caracterización que hizo Nandino de estos poemas como una serie de fotografías, ya que aquí la memoria visual del poeta actúa como una placa fotográfica, capturando y preservando la imagen de otra persona:

Yo te dejaba ir, los ojos cerrando, al fin te guardaba

la placa de mi retina. ¡Saldrías cercana y clara!

En todos los demás casos, sin embargo, el medio es la pintura. "Soledad" y los dos poemas titulados "Cuadro" sugieren la posibilidad de conferir permanencia a la cara humana inmortalizándola en un retrato en el lienzo: en efecto, el primer "Cuadro" habla del sujeto femenino como "fuera 
del tiempo" y por lo tanto inmune a cualquier alteración. "Interior" y "Cézanne" representan intentos de inmovilizar la realidad inanimada al modo de una naturaleza muerta. Pero la vida misma no se detiene por completo. Tratar de pintarla en un contexto bidimensional produce lo contrario de la vida real: es decir, una naturaleza muerta. Al revelar el poeta la película utilizada por su retina para sacarle una fotografía al rostro de la mujer, encuentra que la imagen resultante no es "cercana y clara", sino "borrosa y lejana, / ¡no era nada! ("Lugares" III). El retrato queda básicamente como un fenómeno irreal que conduce a una precaria existencia a sólo un paso del tiempo amenazante. "Sólo la edad te rodea", dice el poeta al rostro que le clava la vista en el primer "Cuadro"; después advierte a la mujer que no respire, para evitar que el aire inhalado la haga envejecer y morir la muerte común al resto del mundo. La misma sensación del tiempo asomándose por los alrededores afecta la contemplación que hace el poeta de la fruta que descansa inmóvil en su plato, y rompe bruscamente en sus pensamientos con la fuerza de una verdad ineludible:

\author{
¡Ay si el frutero \\ se resignara a no ser verdadero! \\ Mas cada fruto \\ quiere morir a tiempo porque sabe \\ que su verano es pasajero. \\ ("Interior")
}

La preocupación de Villaurrutia por la forma tiene un efecto notable, aunque más limitado, en los elementos específicamente estructurales de Reflejos. El título "Suite del insomnio", por ejemplo, sugiere una profunda necesidad de organizar impresiones sensoriales fugaces y fortuitas en patrones preconcebidos y reconocibles. En este caso el poeta torna a las formas musicales como hará en sus nocturnos. Los cortos poemas incluidos en esta suite, al igual que otros muchos en Reflejos, han sido vistos como intentos de imitar la construcción del baikai japonés. ${ }^{9}$ También notamos una incipiente conciencia del problema del lenguaje - de la tendencia

\footnotetext{
9 Véanse Giuseppe Bellini, "La poesia di Xavier Villaurrutia", Letterature moderne, X, 1 (enero-febrero, 1960), p. 21, y Gloria Ceide Echevarria, El haikai sn la lirica mexicana (México, 1967), pp. 85-89. Entre las observaciones de Ceide Echevarría cabe notar en especial el reconocimiento de la influencia del poeta José Juan Tablada, quien, según el propio Villaurtutia, mantiene en la poesía mexicana su "huella" por haber "trasplantado" a ella la téenica del baikai (citado por Ceide Echevarría, pp. 88-89).
} 
de las palabras a jugarles tretas a los significados y, por consiguiente, la necesidad de sujetarlas a la disciplina poética. Esto se manifiesta más marcadamente en los juegos de palabras de "Poesía", que anuncian los de Nostalgia:

me estoy mirando mirarme por mil Argos, por mí largos segundos

y me deja

sin más pulso ni voz y sin más cara

sin máscara como un hombre desnudo

en medio de una calle de miradas.

Finalmente, comprendemos que estamos en presencia de cierta actitud frente a la versificación. En este momento temprano podemos ver a Villaurrutia reaccionando contra el metro fácil y los arreglos de rima tan abundantes en la poesía romántica y modernista tardias, y que aparecieron en los "Primeros poemas". La ausencia de patrones en los versos de estos poemas se explica por estar el poeta rebelándose contra una tradición que insistía en la regularidad del ritmo y predictabilidad de la rima hasta el tedio. La notable variación en la longitud de los versos de una composición como "Poesía", o entre "Interior" y la "Suite del insomnio", por ejemplo, da la clara impresión de que el poeta sabe bien lo que quiere evitar, pero, como todavía no se ha entregado por completo a nuevos patrones de metro y rima, debe conformarse, al menos por el momento, con una versificación experimental y tentativa, que se estabilizará parcialmente en Nostalgic con la introducción del soneto y la décima. No se puede afirmar, sin embargo, que en Reflejos predomine el versolibrismo. Merlin Forster observa que, mientras "por toda la colección es notable la falta casi completa de esquemas fijos de estrofa, metro o rima", el gran número de versos y estrofas que en su conjunto constituyen una totalidad sin estructurar, pero que individualmente se adhieren a madelos convencionales de longitud y rima, coloca esta poesía en la "modalidad semilibre" que Navarro Tomás distingue del verso libre. ${ }^{10}$ La voluntad de forma del poeta, aunque menos perceptible para el lector por esta razón, opera de todos modos en grado significativo. En

10 Los Contemporáneos; 1920-1932: Perfil de un experimento vanguardista mexicano (México, 1964), p. 86. Cf. Tomás Navarro Tomás, Métrica española (Syracuse, Nueva York, 1956), p. 13. 
ella vemos de nuevo ese doble aspecto de Reflejos que hemos ido señalando: la afirmación poética que en sí constituye un momento distintivo, y la prayección hacia la que será obra de plena madurez.

EUgene L. MORETTA

Yale University 